\title{
Updated imaging does not affect revision rates in adults undergoing spine surgery for lumbar degenerative disease
}

\author{
Zachary G. Ries, MD, ${ }^{1}$ Steven D. Glassman, MD, Ivan Vasilyev, ${ }^{2}$ Leanne Metcalfe, $\mathrm{PhD},{ }^{2}$ and \\ Leah Y. Carreon, MD, MSc ${ }^{1}$
}

${ }^{1}$ Norton Leatherman Spine Center, Louisville, Kentucky; and ${ }^{2}$ Health Care Service Corporation, Enterprise Clinical Analytics,
Chicago, Illinois

OBJECTIVE Diagnostic workup for lumbar degenerative disc disease (DDD) includes imaging such as radiography, MRI, and/or CT myelography. If a patient has unsuccessful nonoperative treatment, the surgeon must then decide if obtaining updated images prior to surgery is warranted. The purpose of this study was to investigate whether the timing of preoperative neuroimaging altered clinical outcome, as reflected by the subsequent rate of revision surgery, in patients with degenerative lumbar spinal pathology.

METHODS From the Health Care Service Corporation administrative claims database, adult patients (minimum age 55 years old) with lumbar DDD who underwent surgery including posterior lumbar decompression with and without fusion (1-2 levels) and at least 5 years of continuous coverage after the index surgery were identified. The chi-square test was used to determine differences in revision rates stratified by timing of each imaging procedure relative to the index procedure (< 6 months, 6-12 months, 12-24 months, or > 24 months).

RESULTS Of 28,676 cases identified, $5128(18 \%)$ had revision surgery within 5 years. The timing of preoperative MRI or plain radiography was not associated with revision surgery. Among the entire cohort, there was a lower incidence of revision surgery in patients who had a CT myelogram within 1 year prior to the index surgery $(p=0.017)$. This observation was strongest in patients undergoing decompression only $(p=0.002)$, but not significant in patients undergoing fusion ( $p$ $=0.845)$.

CONCLUSIONS Routine reimaging prior to surgery, simply because the existing MRI is 6-12 months old, may not be beneficial, at least as reflected in subsequent revision rates. The study also suggests that there may be a subset of patients for whom preoperative CT myelography reduces revision rates. This topic has important financial implications and deserves further study in a more granular data set.

https://thejns.org/doi/abs/10.3171/2018.8.SPINE18586

KEYWORDS lumbar fusion; lumbar decompression; diagnostic imaging; revision surgery; administrative database; degenerative

工 UMBAR degenerative disc disease (DDD) includes degenerative conditions of the lumbar spine, such varying degrees of canal stenosis, endplate sclerosis, osteophyte formation, facet hypertrophy, disc degeneration, and ligamentum flavum thickening.? Symptoms can include back and leg pain, neurogenic claudication, numbness, weakness, and gait abnormalities. ${ }^{3,7,12}$ Radiographic workup of the degenerative lumbar spine includes plain radiographs, MRI, and CT with or without myelography.
Initial treatment strategies are generally nonoperative, including combinations of antiinflammatory medications, physical therapy, aerobic conditioning, and injections. ${ }^{3,7,12}$ Some patients fail nonoperative treatment and may require surgical intervention. These interventions typically consist of decompression with or without fusion.

Depending on the time interval from initial imaging to surgical treatment, the surgeon may elect to repeat imaging studies to evaluate for interval changes and aid in preoperative planning. Although repeat imaging is warranted in cases in which symptoms have changed or new symp-

ABBREVIATIONS CPT = Current Procedural Terminology; $D D D=$ degenerative disc disease; $\mathrm{HCSC}=$ Health Care Service Corporation. SUBMITTED May 9, 2018. ACCEPTED August 1, 2018.

INCLUDE WHEN CITING Published online November 16, 2018; DOI: 10.3171/2018.8.SPINE18586. 
TABLE 1. Procedures included in the study and CPT codes

\begin{tabular}{|c|c|}
\hline CPT Code & Procedure \\
\hline 22612 & $\begin{array}{l}\text { Arthrodesis, posterior or posterolateral technique, } \\
\text { lumbar }\end{array}$ \\
\hline 22614 & $\begin{array}{l}\text { Arthrodesis, posterior or posterolateral technique, } \\
\text { each additional vertebral segment }\end{array}$ \\
\hline 22630 & Arthrodesis, posterior interbody technique, lumbar \\
\hline 22632 & $\begin{array}{l}\text { Arthrodesis, posterior interbody technique, each ad- } \\
\text { ditional interspace }\end{array}$ \\
\hline 22634 & $\begin{array}{l}\text { Combined fusion, posterolateral fusion, w/ posterior } \\
\text { interbody fusion each additional interspace/segment }\end{array}$ \\
\hline 22840 & $\begin{array}{l}\text { Posterior instrumentation nonsegmental instrumenta- } \\
\text { tion }\end{array}$ \\
\hline 22630 & Posterior interbody fusion, lumbar \\
\hline 22632 & Posterior interbody fusion, lumbar each additional level \\
\hline 63005 & $\begin{array}{l}\text { Laminectomy w/o facetectomy, foraminotomy, or disc- } \\
\text { ectomy, lumbar, except for spondylolisthesis } 1 \text { or } 2 \\
\text { vertebral segments }\end{array}$ \\
\hline 63012 & Laminectomy w/ removal of abnormal facets, lumbar \\
\hline 63017 & $\begin{array}{l}\text { Laminectomy w/o facetectomy, foraminotomy, or disc- } \\
\text { ectomy, lumbar, except for spondylolisthesis more } \\
\text { than } 2 \text { vertebral segments }\end{array}$ \\
\hline 63030 & $\begin{array}{l}\text { Laminotomy (hemilaminectomy), including partial fac- } \\
\text { etectomy, foraminotomy, \&/or excision of herniated } \\
\text { disc, lumbar } 1 \text { interspace }\end{array}$ \\
\hline 63035 & $\begin{array}{l}\text { Laminotomy (hemilaminectomy), including partial fac- } \\
\text { etectomy, foraminotomy, \&/or excision of herniated } \\
\text { disc, lumbar each additional interspace }\end{array}$ \\
\hline 63047 & $\begin{array}{l}\text { Laminectomy, facetectomy, \& foraminotomy, lumbar } \\
\text { single vertebral segment }\end{array}$ \\
\hline 63048 & $\begin{array}{l}\text { Laminectomy, facetectomy, \& foraminotomy, lumbar } \\
\text { each additional segment }\end{array}$ \\
\hline \multicolumn{2}{|l|}{$\begin{array}{l}\text { Radiology } \\
\text { CPT codes } \\
\text { included }\end{array}$} \\
\hline 72148 & MRI lumbar spine w/o contrast \\
\hline 72149 & MRI lumbar spine w/ contrast \\
\hline 72158 & MRI lumbar spine w/ \& w/o contrast \\
\hline 72100 & Lumbar spine AP \& lateral \\
\hline 72110 & Lumbar spine w/ oblique \\
\hline 72114 & Lumbar spine w/ bending \\
\hline 72120 & Lumbar spine, bending views only \\
\hline 72255 & $\begin{array}{l}\text { Myelography, thoracic, radiological supervision \& } \\
\text { interpretation }\end{array}$ \\
\hline 72129 & $\mathrm{CT}$, thoracic spine, w/ contrast material \\
\hline 72265 & $\begin{array}{l}\text { Myelography, lumbosacral, radiological supervision \& } \\
\text { interpretation }\end{array}$ \\
\hline 72132 & $\mathrm{CT}$, lumbar spine, w/ contrast material \\
\hline 62284 & Injection procedure for myelography \&/or CT, spinal \\
\hline
\end{tabular}

$\mathrm{AP}=$ anterior-posterior. toms have developed, controversy exists as to whether these costly imaging studies should be repeated for the sake of an "updated study" in the absence of new symptomatology. This issue is particularly important in the current healthcare environment emphasizing value-based decision-making.

Although it is reasonable to repeat imaging in the presence of new or changed symptoms, there are limited data and no evidence-based recommendation as to the need for "updated" preoperative diagnostic imaging in patients undergoing surgery for lumbar DDD. In part, the absence of clear guidance reflects the difficulty in selecting a metric to evaluate the timing of neuroimaging. Furthermore, most available spine registries and data sets do not collect granular detail regarding preoperative imaging. The purpose of this study was to investigate whether the timing of preoperative neuroimaging altered clinical outcome, as reflected by the subsequent rate of revision surgery, in patients with degenerative lumbar spinal pathology.

\section{Methods \\ Data Collection}

We queried the claims database of a leading healthcare insurance provider, the Health Care Service Corporation (HCSC), to evaluate the relationship between preoperative imaging studies and revision surgery. HCSC is the largest customer-owned health insurer in the US and fourth largest overall, operating in Illinois, Montana, New Mexico, Oklahoma, and Texas. Any healthcare system encounter, including office visits, diagnostic procedures, hospital admissions, and pharmacy prescriptions for which an insurance claim is filed with HCSC by a subscriber, is entered into the administrative claims database. These data are collected for the primary purpose of billing and administration of insurance claims. However, administrative databases can be used to evaluate healthcare delivery and costs.

We identified adult patients 55 years and older with lumbar DDD who underwent surgical treatment including posterior spinal decompression alone and posterior spinal decompression with fusion over 1-2 levels using Current Procedural Terminology (CPT) codes (Table 1). All patients had one or more of the following diagnoses: lumbar spinal stenosis, lumbar spondylolisthesis, lumbar DDD, or lumbar degenerative scoliosis. Additionally, all patients had at least 2 years of continuous coverage prior to the index surgery and 5 years of continuous coverage in the HCSC system after the index surgery. Exclusion criteria included procedures involving 3 levels or more, anterior procedures, and procedures involving spinal osteotomy. Within this cohort, we identified each spinal imaging modality obtained within 2 years prior to the index operation. Specifically, we sought to identify when the most recent set of plain radiographs, MRI, and/or CT myelogram was obtained in relation to the index procedure.

Patients were stratified into four groups based on the timing of each preoperative imaging study in relation to the index procedure: $<6$ months, 6-12 months, 12-24 months, and $>24$ months. Each imaging modality was evaluated independently and divided into 5 categories: 
TABLE 2. Summary of demographic data

\begin{tabular}{lccc}
\hline \multicolumn{1}{c}{ Variable } & Revision & No Revision & $p$ Value \\
\hline Mean age \pm SD, yrs & $62.4 \pm 7.6$ & $63.1 \pm 7.9$ & $<0.001$ \\
\hline$\%$ females & 55.7 & 55.5 & 0.912 \\
\hline
\end{tabular}

MR image, lumbar radiograph, CT myelogram, any imaging, and no imaging within 24 months prior to the index operation. The percentage of patients undergoing revision surgery within 5 years of the index operation was then determined. Subgroup analyses were performed on patients undergoing decompression only and those patients undergoing decompression and posterolateral fusion.

\section{Statistical Analysis}

Chi-square analysis was used for categorical data to determine differences in the rates of revision surgery within 5 years based on timing of preoperative imaging. A Student t-test was used to compare the means of continuous data between the revision and no-revision cohorts.

\section{Results}

A total of 28,676 patients met inclusion criteria. Demographic data are listed in Table 2. Of the 28,676 patients, a total of $5128(18 \%)$ had a revision operation within 5 years of the index procedure. From this cohort, a total of 17,190 patients had a decompression without fusion, of whom $3045(18 \%)$ had a revision within 5 years. A total of 11,486 patients had a lumbar fusion procedure, with 2083 (18\%) undergoing revision within 5 years. There were no significant differences in mean time from most recent MRI to surgery $(148 \pm 280$ vs $136 \pm 260$ days, $\mathrm{p}=0.072)$, most recent radiographs to surgery $(217 \pm 488$ vs $202 \pm 448$ days, $\mathrm{p}=0.185)$, most recent CT myelogram $(59 \pm 295$ vs $49 \pm 281$ days, $\mathrm{p}=0.158$ ), or most recent form of any imaging (99 \pm 237 vs $98 \pm 236$ days, $\mathrm{p}=0.919)$ between patients undergoing revision and those not undergoing revision surgery.

The timing of MRI and plain radiography was not associated with revision surgery out to 5 years after the index operation. The only significant differences in the timing of image acquisition and revision surgery were observed for CT myelograms obtained for the cohort as a whole (Table 3) as well as the decompression-only cohort (Table 4). Patients were less likely to have a revision operation if a CT myelogram was obtained within 1 year of the index operation in both the entire cohort $(\mathrm{p}=0.017)$ and the decompression-only cohort $(\mathrm{p}=0.002)$. This significance was not observed in the cohort of patients undergoing fusion surgery $(\mathrm{p}=0.845$, Table 5$)$.

\section{Discussion}

We found a 5-year revision rate of $18 \%$ for both patients undergoing decompression without fusion and those who underwent a fusion procedure. This is similar to previous studies in which revision rates varied between $10 \%$ and $38 \%$ for various degenerative conditions of the lumbar
TABLE 3. Number of revisions stratified by type and timing of imaging studies for the entire surgical cohort

\begin{tabular}{lrrr}
\hline \multicolumn{1}{c}{ Imaging Study } & Revision & No Revision & p Value \\
\hline MRI (mos) & & & 0.097 \\
\hline$<6$ & 3887 & 17,877 & \\
\hline $6-12$ & 530 & 2222 & \\
\hline $12-24$ & 185 & 732 & \\
\hline$>24$ & 105 & 446 & \\
\hline Radiography (mos) & & & 0.240 \\
\hline$<6$ & 2932 & 13,334 & \\
\hline $6-12$ & 428 & 1893 & \\
\hline $12-24$ & 340 & 1393 & \\
\hline$>24$ & 460 & 1934 & \\
\hline CT myelography (mos) & & & 0.017 \\
\hline$<6$ & 627 & 2342 & \\
\hline $6-12$ & 41 & 197 & \\
\hline $12-24$ & 50 & 142 & \\
\hline$>24$ & 109 & 309 & \\
\hline Any imaging (mos) & & & 0.646 \\
\hline$<6$ & 4523 & 20,431 & \\
\hline $6-12$ & 266 & 1257 & \\
\hline $12-24$ & 91 & 416 & \\
\hline$>24$ & 68 & 357 & \\
\hline No imaging (mos) & & & \\
\hline$<6$ & 605 & 3117 & \\
\hline $6-12$ & 339 & 1860 & \\
\hline $12-24$ & 248 & 1444 & \\
\hline$>24$ & 180 & 1087 & \\
\hline
\end{tabular}

Boldface type indicates statistical significance.

spine. ${ }^{4-6,8-10,13,14,16}$ While numerous studies have reported on risk factors for revision surgery, this is the first report examining associations between type and timing of spinal imaging with subsequent revision surgery. It is generally accepted that the workup of patients with advanced lumbar degenerative conditions should include plain radiography and at least one form of advanced neuroimaging, such as MRI or CT, with or without myelography. However the timing of these studies, and in particular the need for "updated" or current imaging in preparation for surgery, has not been established.

Given that most patients pursue nonoperative treatment after an initial imaging study establishes the diagnosis, the surgeon must decide if diagnostic imaging needs to be repeated prior to any subsequent surgical intervention. Occasionally, the decision to get updated images is noncontroversial, such as with the development of a new symptom, significant progression of current symptoms, or when the most recent imaging studies are several years old. However, data- and evidence-based recommendations regarding the need for repeat imaging are lacking for patients progressing to surgery in the absence of new neurological symptoms.

Establishing the value or appropriate timing of "up- 
TABLE 4. Number of revisions stratified by type and timing of different imaging studies for the decompression-only cohort

\begin{tabular}{|c|c|c|c|}
\hline Decompression Cohort & Revision & No Revision & p Value \\
\hline MRI (mos) & & & 0.338 \\
\hline$<6$ & 2485 & 11,551 & \\
\hline $6-12$ & 230 & 1020 & \\
\hline $12-24$ & 78 & 289 & \\
\hline$>24$ & 48 & 218 & \\
\hline Radiography (mos) & & & 0.092 \\
\hline$<6$ & 1648 & 7651 & \\
\hline $6-12$ & 257 & 1017 & \\
\hline $12-24$ & 201 & 830 & \\
\hline$>24$ & 292 & 1251 & \\
\hline CT myelography (mos) & & & 0.002 \\
\hline$<6$ & 282 & 1084 & \\
\hline $6-12$ & 13 & 80 & \\
\hline $12-24$ & 22 & 49 & \\
\hline$>24$ & 59 & 140 & \\
\hline Any imaging (mos) & & & 0.307 \\
\hline$<6$ & 2738 & 12,636 & \\
\hline $6-12$ & 134 & 611 & \\
\hline $12-24$ & 42 & 193 & \\
\hline$>24$ & 29 & 195 & \\
\hline No imaging (mos) & & & 0.245 \\
\hline$<6$ & 307 & 1509 & \\
\hline $6-12$ & 173 & 898 & \\
\hline $12-24$ & 131 & 705 & \\
\hline$>24$ & 102 & 510 & \\
\hline
\end{tabular}

Boldface type indicates statistical significance.

dated" neuroimaging requires a metric that reflects the incremental benefit associated with any additional imaging study. This represents a challenge because our standard measure of benefit, i.e., patient-reported outcomes, only very indirectly reflects the timing of neuroimaging in most cases. The primary assumption in our study design is that the need for revision surgery should be a reasonably direct reflection of accurate or inaccurate preoperative neuroimaging. That is, if the critical pathology has changed and that change is missed in the preoperative assessment, the patients' symptoms will persist and more likely result in revision surgery.

The primary finding from this study is that the timing of preoperative MRI was not associated with revision surgery up to 5 years postoperatively. This suggests that, assuming no change in symptoms, routine reimaging simply because the previous MRI was performed 6 months or 1 year prior to the index operation may not be needed. This may have important implications for reducing healthcare costs in the future and represents an area for future study using a more granular data set.

A secondary finding of this study was that there appears to be a subset of patients who benefit from a CT myelogram within 12 months of surgical intervention. We
TABLE 5. Number of revisions stratified by type and timing of different imaging studies for the fusion cohort

\begin{tabular}{|c|c|c|c|}
\hline Fusion Cohort & Revision & No Revision & $p$ Value \\
\hline MRI (mos) & & & 0.308 \\
\hline$<6$ & 1402 & 6326 & \\
\hline $6-12$ & 300 & 1202 & \\
\hline $12-24$ & 107 & 443 & \\
\hline$>24$ & 57 & 228 & \\
\hline Radiography (mos) & & & 0.178 \\
\hline$<6$ & 1284 & 5683 & \\
\hline $6-12$ & 171 & 876 & \\
\hline $12-24$ & 139 & 563 & \\
\hline$>24$ & 168 & 683 & \\
\hline CT myelography (mos) & & & 0.845 \\
\hline$<6$ & 345 & 1258 & \\
\hline $6-12$ & 28 & 117 & \\
\hline $12-24$ & 28 & 93 & \\
\hline$>24$ & 50 & 169 & \\
\hline Any imaging (mos) & & & 0.688 \\
\hline$<6$ & 1785 & 7795 & \\
\hline $6-12$ & 132 & 646 & \\
\hline $12-24$ & 49 & 223 & \\
\hline$>24$ & 39 & 162 & \\
\hline No imaging (mos) & & & 0.109 \\
\hline$<6$ & 298 & 1608 & \\
\hline $6-12$ & 166 & 962 & \\
\hline $12-24$ & 117 & 739 & \\
\hline$>24$ & 78 & 577 & \\
\hline
\end{tabular}

found a lower revision rate in the entire patient cohort as well as the decompression-only cohort in patients undergoing CT myelography within 12 months of their index procedure. This finding deserves further investigation, as several possibilities exist to explain the observation.

One explanation for lower revision rates in patients who had CT myelography within 1 year of surgery may be a better surgical plan that recognizes stenosis or instability identified with axial loading. CT myelography demonstrates weight-bearing accentuated compression as well as dynamic instability, which may reveal an adjacent level of compression not detected on standard supine MRI. Similar observations have been previously demonstrated in the literature.

Merkle and associates found that 137 additional stenotic segments were diagnosed in 64 patients by standing myelography, suggesting that stenosis will be underestimated in $64 \%$ of patients if they undergo routine lumbar spine MRI. Additionally, 23 patients with inconclusive spine MRI results had lumbar spinal stenosis on standing myelography. ${ }^{15}$ Previous studies have also reported on spontaneous reduction of low-grade spondylolisthesis with supine positioning required for MRI.,11 Segebarth and associates reported that of 109 patients with degenerative spondylolisthesis diagnosed on flexion/extension 
lumbar radiographs, only 78 had accompanying spondylolisthesis on MRI. ${ }^{17}$

Given that this finding was found in the decompression-only group, the CT myelogram may have persuaded the surgeon to include additional levels in the decompression or add a fusion based on newly recognized instability. Both of these scenarios are more likely in cases in which alignment changes with upright posture (scoliosis or spondylolisthesis). Upright full-length scoliosis and flexion/extension radiographs can assist in identification of subtle alterations in alignment or instability that could impact surgical decision-making. However, prior work demonstrated a significant surgical cohort based solely on preoperative MRI with an accompanying 5-year revision rate of $41.8 \%$, providing further evidence that some form of preoperative weight-bearing study improves survivorship. ${ }^{2}$ The results of this study seem to corroborate these previous findings and suggest that there may be a subset of patients for whom a preoperative weight-bearing study such as a CT myelogram reduces revision rates and represents an area of further study.

This study has several limitations, many of which are inherent to the use of an administrative claims database. First and foremost, the reasons for both the index surgery and the revision surgery could not be determined. Potential indications for revision include instability requiring fusion, inadequate decompression requiring same-level revision, or adjacent-level pathology requiring additional-level surgery. We also did not have access to patientspecific factors including disability status, comorbidities, history of previous spine surgery, symptomatology, and patient-reported outcomes as these could all influence revision rates and determine why one type of imaging study was obtained over another. There was also limited information about patient demographics in the database other than age and sex.

The inability to determine what type of preoperative lumbar radiographs were obtained is another limitation. Perhaps revision rates would have differed based on flexion/extension or upright full-length radiographs compared to supine-only radiographs or only advanced imaging. Additionally, persistent symptoms in patients with lumbar disc herniations (CPT codes 63030 and 63035) may necessitate updated imaging to demonstrate the continued presence of a compressive lesion. There may have also been HCSC patients who underwent an index lumbar procedure who were subsequently lost to follow-up and therefore excluded from the analysis. Diagnostic imaging performed out of network would not have been captured.

\section{Conclusions}

This is the first study to evaluate the timing and type of preoperative imaging studies to assess the influence on revision rates in patients with lumbar DDD. This study also represents a unique collaborative effort between a tertiary spine center and a leading insurance provider to address clinical issues relevant to healthcare providers as well as a reduction in healthcare costs. In the absence of new or changed symptoms, the primary finding of this study is that repeating MRI because it is 6 months or 1 year old prior to a 1- or 2-level lumbar surgery does not appear to alter subsequent revision rates. Additionally, there may be a subset of patients for whom a preoperative CT myelogram reduces revision rates. Identifying these patients should be a focus of further studies with a more detailed data set.

\section{References}

1. Bendo JA, Ong B: Importance of correlating static and dynamic imaging studies in diagnosing degenerative lumbar spondylolisthesis. Am J Orthop 30:247-250, 2001

2. Bunch JT, Glassman SD, Underwood HR, Metcalfe LN, Ondra S, Vasilyev I, et al: Preoperative full-length standing radiographs and revision rates in lumbar degenerative scoliosis. J Neurosurg Spine 28:581-585, 2018

3. Covaro A, Vilà-Canet G, de Frutos AG, Ubierna MT, Ciccolo F, Caceres E: Management of degenerative lumbar spinal stenosis: an evidence-based review. EFORT Open Rev 1:267-274, 2017

4. Deyo RA, Martin BI, Kreuter W, Jarvik JG, Angier H, Mirza SK: Revision surgery following operations for lumbar stenosis. J Bone Joint Surg Am 93:1979-1986, 2011

5. Gerling MC, Leven D, Passias PG, Lafage V, Bianco K, Lee A, et al: Risk factors for reoperation in patients treated surgically for degenerative spondylolisthesis: a subanalysis of the 8 -year data from the SPORT trial. Spine (Phila Pa 1976) 42:1559-1569, 2017

6. Gerling MC, Leven D, Passias PG, Lafage V, Bianco K, Lee A, et al: Risk factors for reoperation in patients treated surgically for lumbar stenosis: a subanalysis of the 8-year data from the SPORT trial. Spine (Phila Pa 1976) 41:901-909, 2016

7. Issack PS, Cunningham ME, Pumberger M, Hughes AP, Cammisa FP Jr: Degenerative lumbar spinal stenosis: evaluation and management. J Am Acad Orthop Surg 20:527535, 2012

8. Kim CH, Chung CK, Park CS, Choi B, Hahn S, Kim MJ, et al: Reoperation rate after surgery for lumbar spinal stenosis without spondylolisthesis: a nationwide cohort study. Spine J 13:1230-1237, 2013

9. Kim CH, Chung CK, Park CS, Choi B, Kim MJ, Park BJ: Reoperation rate after surgery for lumbar herniated intervertebral disc disease: nationwide cohort study. Spine (Phila Pa 1976) 38:581-590, 2013

10. Leven D, Passias PG, Errico TJ, Lafage V, Bianco K, Lee A, et al: Risk factors for reoperation in patients treated surgically for intervertebral disc herniation: a subanalysis of eightyear SPORT data. J Bone Joint Surg Am 97:1316-1325, 2015

11. Lowe RW, Hayes TD, Kaye J, Bagg RJ, Luekens CA: Standing roentgenograms in spondylolisthesis. Clin Orthop Relat Res (117): 80-84, 1976

12. Madigan L, Vaccaro AR, Spector LR, Milam RA: Management of symptomatic lumbar degenerative disk disease. J Am Acad Orthop Surg 17:102-111, 2009

13. Malter AD, McNeney B, Loeser JD, Deyo RA: 5-year reoperation rates after different types of lumbar spine surgery. Spine (Phila Pa 1976) 23:814-820, 1998

14. Martin BI, Mirza SK, Comstock BA, Gray DT, Kreuter W, Deyo RA: Reoperation rates following lumbar spine surgery and the influence of spinal fusion procedures. Spine (Phila Pa 1976) 32:382-387, 2007

15. Merkle M, Maier G, Danz S, Kaminsky J, Tatagiba MS, Hebela NM, et al: The value of dynamic radiographic myelography in addition to magnetic resonance imaging in detection lumbar spinal canal stenosis: a prospective study. Clin Neurol Neurosurg 143:4-8, 2016 
16. Sato S, Yagi M, Machida M, Yasuda A, Konomi T, Miyake A, et al: Reoperation rate and risk factors of elective spinal surgery for degenerative spondylolisthesis: minimum 5-year follow-up. Spine J 15:1536-1544, 2015

17. Segebarth B, Kurd MF, Haug PH, Davis R: Routine upright imaging for evaluating degenerative lumbar stenosis: incidence of degenerative spondylolisthesis missed on supine MRI. J Spinal Disord Tech 28:394-397, 2015

\section{Disclosures}

Dr. Glassman reports being an employee of Norton Healthcare; being a consultant for and receiving royalties from Medtronic; and being Past President of the Scoliosis Research Society. Dr. Carreon reports being an employee of Norton Healthcare; being a consultant for AOSpine; receiving funds for travel from the University of Southern Denmark and University of Louisville; being a member of the Editorial Advisory Board for Spine Deformity, The Spine Journal, and Spine; being a member of the University of Louisville IRB; and being a member of the Research Committee for the Scoliosis Research Society.

\section{Author Contributions}

Conception and design: Ries, Glassman. Acquisition of data: Vasilyev, Metcalfe. Analysis and interpretation of data: Carreon, Ries, Vasilyev. Drafting the article: Ries. Critically revising the article: all authors. Reviewed submitted version of manuscript: all authors. Approved the final version of the manuscript on behalf of all authors: Carreon. Statistical analysis: Vasilyev. Administrative/ technical/material support: Carreon, Glassman, Metcalfe. Study supervision: Glassman, Metcalfe.

\section{Correspondence}

Leah Y. Carreon: Norton Leatherman Spine Center, Louisville, KY. leah.carreon@nortonhealthcare.org. 